\title{
Carbon dioxide laser application enhances the effect of silane primer on the shear bond strength between porcelain and composite resin
}

\author{
Jian-Rong CHEN', Kenji OKA², Takanori KAWANO², Takaharu GOTO² and Tetsuo ICHIKAWA² \\ ${ }^{1}$ Department of Prosthodontics, School of Stomatology, Tongji University, No. 399 Middle Yanchang Road, Shanghai 200072, R.P. China \\ ${ }^{2}$ Department of Oral and Maxillofacial Prosthodontics and Oral Implantology, The University of Tokushima, Institute of Health Biosciences, 3-18-15 \\ Kuramoto-cho, Tokushima 770-8504, Japan \\ Corresponding author, Takaharu GOTO; E-mail: tak510@dent.tokushima-u.ac.jp
}

\begin{abstract}
The purpose of this study was to evaluate the effect of carbon dioxide laser irradiation on the performance of silane coupling agent as an adhesion promoter. The carbon dioxide laser used in this study was Opelaser 03S II, which irradiated the silane coupling agent applied on the adhesive surface of porcelain. Before and after thermal cycling, shear bond strength was measured using a universal testing machine. Without primer treatment, most of the specimens failed adhesively before reaching the end of the thermal cycling period. For the specimens irradiated with carbon dioxide laser after primer treatment, their shear bond strengths before and after thermal cycling were higher than those treated with primer only — with a significantly pronounced difference between these two groups especially after thermal cycling. Therefore, a combined surface treatment which involved silane application followed by laser treatment was feasible and efficacious for chairside porcelain repair.
\end{abstract}

Keywords: Carbon dioxide laser, Shear bond strength, Silane coupling agent

\section{INTRODUCTION}

Patient demand for esthetic dentistry has increased. For many years, the most predictable and durable esthetic restoration of anterior teeth has been achieved with porcelain-fused-to-metal crowns ${ }^{1)}$. However, fracture of the brittle ceramic veneer occasionally occurs. Failure resulting from porcelain fracture has been reported to range from $2.3 \%$ to $8 \%$, and the cause of clinical fractures of veneering porcelain on porcelainfused-to-metal crowns is often multifactorial ${ }^{2-4}$. Notwithstanding the spectrum of different causative factors, adhesion of composite resin to porcelain has been identified as one technique to repair fractured porcelain veneers ${ }^{5,6}$.

To improve the bond strength of composite resin to porcelain, porcelain surface treatments such as diamond roughening, air-particle abrasion with aluminum oxide, and etching with acids have been investigated under in vitro conditions ${ }^{7-9)}$. Recently, silane coupling agents were also introduced to enhance the bond strength of composite resins to silica-based ceramics $^{10,11)}$. To accelerate the mechanism of chemical interaction between silane and the porcelain surface, the reaction may be catalyzed by heating. Heat treatment at $100^{\circ} \mathrm{C}$ has been shown to consolidate three layers of silane into a monolayer without any interphase layer, thereby increasing the bond strength of composite resin to porcelain ${ }^{12)}$. However, hightemperature heat treatment of silane is not feasible for chairside porcelain repair.

Due to the infeasibility of high-temperature silane heat treatment as a chairside procedure, attention was thus turned to the potential use of laser technology. Since the invention of the first laser in 1960, the use of lasers for dental applications has increased rapidly. Today, after decades of steady progress in laser technology, more than 600 laser media types —which can emit laser radiation of varying wavelengths- are known ${ }^{13,14)}$. Amongst the 10 different types of lasers used in medicine, carbon dioxide laser is one of them. It emits radiation at a wavelength of $10,600 \mathrm{~nm}$ which is readily absorbed by water. As soft tissue is $75 \%$ to $90 \%$ water, about $98 \%$ of the energy is converted to heat when it is absorbed by the water molecules in the tissue, causing water in the tissue being irradiated to evaporate into steam on the tissue surface. This meant that only the tissue surface was affected, hence reducing the risk of deep tissue injury ${ }^{15)}$.

In the present study, carbon dioxide laser was applied to render the heat treatment required to increase bond strength on silane-treated porcelain surfaces. The objectives of this study were to measure the shear bond strength of porcelain-composite interface before and after thermal cycling and evaluate the effect of carbon dioxide laser irradiation on the performance of silane coupling agent as an adhesion promoter.

\section{MATERIALS AND METHODS}

Table 1 lists the materials used in this study. The carbon dioxide laser used was Opelaser 03S II (Yoshida Corp., Tokyo, Japan), which had a wavelength of 10,600 nm. Porcelain blocks were fabricated from GN-I Ceramic Block $(13 \times 10 \times 17 \mathrm{~mm})$ for GN-I CAD/CAM system (GC Corp., Tokyo, Japan), and Imperva Porcelain Primer (Shofu Inc., Kyoto, Japan) was used as the silane coupling agent. A light-polymerized composite resin (Lite-Fil II A, Shofu Inc., Kyoto, 
Table 1 Materials used

\begin{tabular}{lll}
\hline Product name & Manufacturer & Lot number \\
\hline GN-1 Ceramic Block & GC Corp., Tokyo, Japan & 0609083 \\
Imperva Porcelain Primer & Shofu Inc., Kyoto, Japan & 080221 \\
Lite-Fil II A & Shofu Inc., Kyoto, Japan & 110641 \\
\hline
\end{tabular}

Japan), which contained 84 wt\% inorganic filler, was used as the adhesive to porcelain.

\section{Preparation of porcelain surface for resin bonding}

The surfaces of the porcelain blocks to be bonded to the composite resin were polished flat with silicon carbide (SiC) abrasive papers (\#220 to \#800; 3M ESPE, St. Paul, MN, USA) under running water. After ultrasonic cleaning with distilled water for 10 minutes, the flattened surfaces were roughened by air abrasion using $50-\mu \mathrm{m} \mathrm{Al}_{2} \mathrm{O}_{3}$ for 15 seconds under a pressure of $0.2 \mathrm{MPa}$ and at $20 \mathrm{~mm}$ distance.

\section{Test groups}

There were four test groups in this study according to the type of surface treatment applied on the porcelain surface:

Group 1: Porcelain surface was treated with air abrasion only (AA). This group served as a control.

Group 2: Porcelain surface was treated with laser irradiation after air abrasion (AA+L).

Group 3: Porcelain surface was treated with primer after air abrasion (AA+P).

Group 4: Porcelain surface was treated with laser irradiation after air abrasion and primer $(\mathrm{AA}+\mathrm{P}+\mathrm{L})$.

1. Carbon dioxide laser irradiation

In $\mathrm{AA}+\mathrm{L}$ and $\mathrm{AA}+\mathrm{P}+\mathrm{L}$ groups where carbon dioxide laser irradiation was performed, laser was operated in continuous wave mode at a distance of $30 \mathrm{~mm}$ between the porcelain surface and laser beam. Temperature on the porcelain surface was measured using a digital thermal recorder (NR-250, Keyence, Osaka, Japan) by placing the electrode on the porcelain surface.

2. Silane treatment

In $\mathrm{AA}+\mathrm{P}$ and $\mathrm{AA}+\mathrm{P}+\mathrm{L}$ groups where silane treatment was performed, the silane coupling agent was applied on the adhesive surface of porcelain. Specifically in $\mathrm{AA}+\mathrm{P}+\mathrm{L}$ group, primer application on the adhesive surface was followed by carbon dioxide laser irradiation.

\section{Bonding procedure}

A light-polymerized composite resin (Lite-Fil II A, Shofu Inc., Kyoto, Japan) was applied through a transparent matrix tube (5 $\mathrm{mm}$ internal diameter) placed on the flattened surface of the porcelain block. The composite resin was polymerized for 180 seconds with a visible light curing unit ( $\alpha$-Light, Morita, Kyoto, Japan). The longer-than-usual duration of 180 seconds

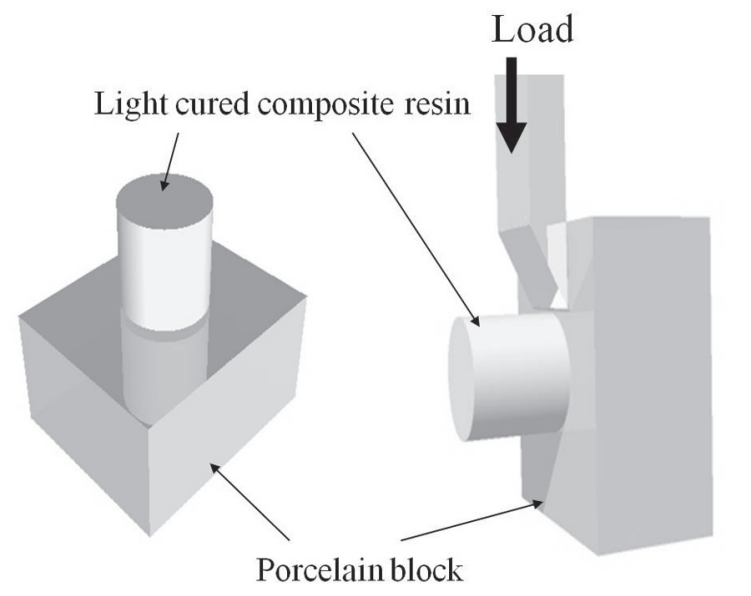

Fig. 1 Schematic diagram of shear bond strength measurement.

was thus employed to ensure that the composite resin was completely polymerized.

After polymerization, the matrix tube was removed, leaving the light-cured composite resin on the treated adhesive surface of the porcelain block. All specimens were stored in $37^{\circ} \mathrm{C}$ distilled water for 24 hours before shear bond strength measurement. Five specimens were prepared for each test group.

\section{Shear bond strength measurement}

After 24-hour storage, all specimens were subjected to a thermal cycling test alternating between temperatures of $4^{\circ} \mathrm{C}$ and $60^{\circ} \mathrm{C}$ water, with a 1 -minute dwell time per bath after 2,000 cycles. Before and after thermal cycling test, shear bond strength was measured using a universal testing machine (AG-100A, Shimadzu Corp., Kyoto, Japan) at a crosshead speed $1.0 \mathrm{~mm} / \mathrm{min}$. Shear force was applied to the interface between the composite resin and porcelain block (Fig. 1), and interfacial bond strength was defined as the maximum load required to debond the two materials.

\section{Surface observation}

At a cut-off value of $0.8 \mathrm{~mm}$ and measurement length of $4.0 \mathrm{~mm}$, the surface roughness and static contact angle of each treated surface were measured using a surface roughness meter (Handy Surf, Tokyo Seimitsu, Tokyo, Japan) and a public domain software "ImageJ" (National Institutes of Health, USA) respectively.

To evaluate compositional changes on each treated 
surface, Raman spectra were recorded using a laser Raman spectroscope (NRS-2100, Jasco Corp., Tokyo, Japan) in the range of 3,500 to $3,800 \mathrm{~cm}^{-1}$. Laser was emitted at $488 \mathrm{~nm}$ with an output of $200 \mathrm{mV}$, and spectral slit width was $100 \mu \mathrm{m}$. After each shear bond strength test, the fractured surfaces were observed using a digital optical microscope (VH-5000, Keyence, Osaka, Japan).

\section{Statistical analysis}

All numerical data were analyzed using a statistical software package (SPSS Ver. 12 for Windows, Tokyo, Japan). The values of each group were compared by two-way analysis of variance (ANOVA) and Duncan's multiple range test at 0.05 level.

\section{RESULTS}

\section{Surface temperature}

Figure 2 shows the temperature changes of the porcelain surface after laser irradiation. At $0.6 \mathrm{~W}$, the maximum temperature of the porcelain surface remained at about $60^{\circ} \mathrm{C}$ regardless of irradiation time. At $1.5 \mathrm{~W}$, surface temperature exceeded $120^{\circ} \mathrm{C}$ in 10 seconds and a carbonized layer was produced on the surface. At $0.8-1.2 \mathrm{~W}$, the maximum temperature ranged between $90^{\circ} \mathrm{C}$ and $100^{\circ} \mathrm{C}$. Moreover at $1.2 \mathrm{~W}$, partial carbonization was observed on the irradiated porcelain surface. Results of this study suggested that the optimal irradiation conditions were $1.0 \mathrm{~W}$ for 20 seconds.

\section{Shear bond strength}

Figure 3 shows the results of shear bond strength between porcelain and composite resin before and after thermal cycling.

Before thermal cycling, the shear bond strength after air abrasion (control AA group) was $0.26 \mathrm{MPa}$, and that after laser irradiation only (AA+L group) was $0.05 \mathrm{MPa}$. After silane treatment only (AA+P group),

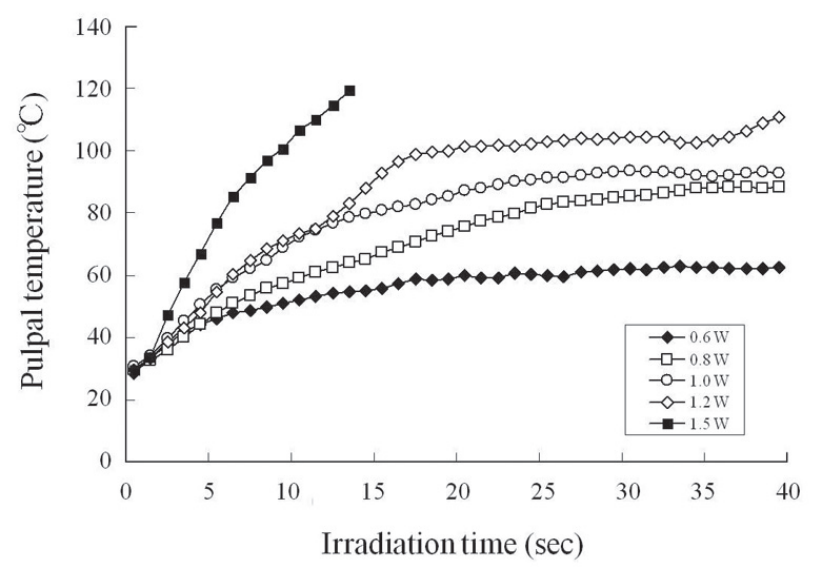

Fig. 2 Changes in surface temperature due to carbon dioxide laser irradiation. shear bond strength was 8.2 $\mathrm{MPa}$; after combined silane and laser applications (AA+P+L group), shear bond strength was 9.7 MPa. In other words, shear bond strength was significantly increased by a combined treatment of silane coupling agent application and laser irradiation.

After thermal cycling, the shear bond strengths of all the test groups were significantly reduced. Most of the specimens without silane treatment (AA and $\mathrm{AA}+\mathrm{L}$ ) failed adhesively before reaching the end of the thermal cycling period. For silane-treated specimens, the shear bond strength of $\mathrm{AA}+\mathrm{P}$ group was $3.6 \mathrm{MPa}$ while that of $\mathrm{AA}+\mathrm{P}+\mathrm{L}$ group was $7.7 \mathrm{MPa}$. For $\mathrm{AA}+\mathrm{P}+\mathrm{L}$ group, statistical analysis revealed that its reduction in shear bond strength after thermal cycling was significantly $(p<0.05)$ smaller than the other test groups.

\section{Surface observation}

1. Fracture surface analysis

For specimens without silane treatment (AA and $\mathrm{AA}+\mathrm{L}$ groups), no cohesive failure was observed in the composite resin before and after thermal cycling. For all specimens with silane treatment $(\mathrm{AA}+\mathrm{P}$ and $\mathrm{AA}+\mathrm{P}+\mathrm{L}$ groups), large areas of cohesive failure were observed on the debonded surfaces before thermal cycling, but cohesive failure was observed in only half of these specimens after thermal cycling. For almost all the laser-irradiated specimens $(\mathrm{AA}+\mathrm{L}$ and $\mathrm{AA}+\mathrm{P}+\mathrm{L}$ groups), cohesive failure was observed in the porcelain substrate before and after thermal cycling (Fig. 4).

2. Surface roughness

Surface roughness ranged between 1.3 and $1.5 \mu \mathrm{m}$ (Fig. $5)$. No significant differences $(p>0.05)$ in mean surface roughness were observed among all the four types of surface treatments. However, it was observed that standard deviations in measurement for carbon dioxide laser treatment groups $(\mathrm{AA}+\mathrm{L}$ and $\mathrm{AA}+\mathrm{P}+\mathrm{L})$ were higher than the other two groups without laser treatment.

In terms of surface morphology, only slight and

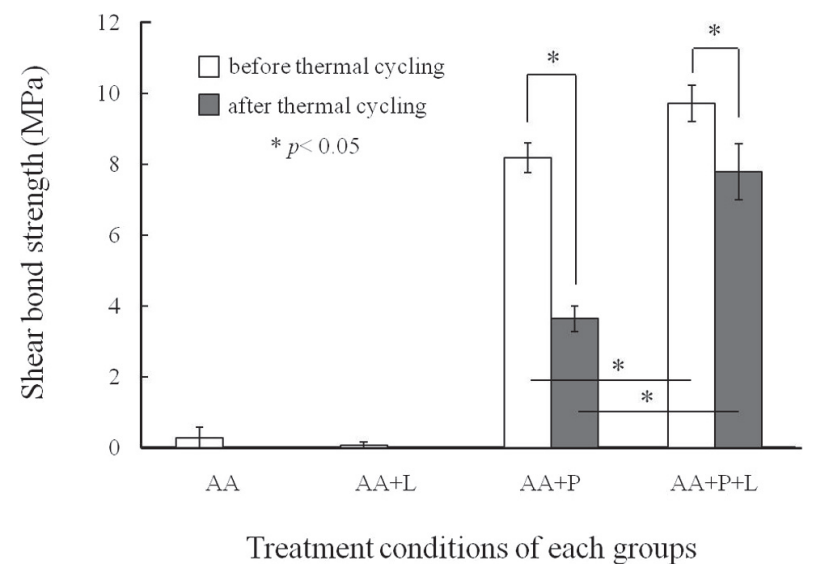

Fig. 3 Shear bond strength results (in $\mathrm{MPa}$ ) before and after thermal cycling. 


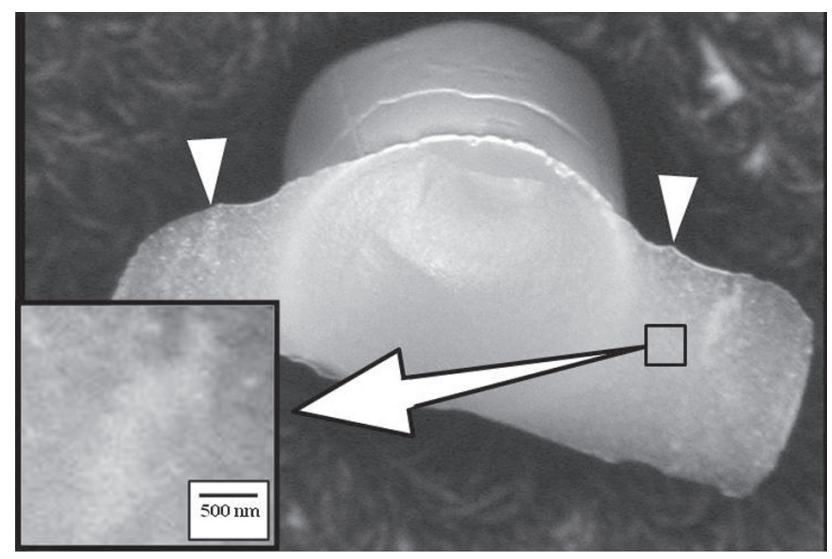

Fig. 4 Photo of the fractured surface of an air-abraded, silane-treated, and laser-irradiated specimen $(\mathrm{AA}+\mathrm{P}+\mathrm{L})$ after thermal cycling (arrowheads: porcelain substrate). The magnified image (original magnification $\times 500$ ) shows cohesive failure in the porcelain substrate.

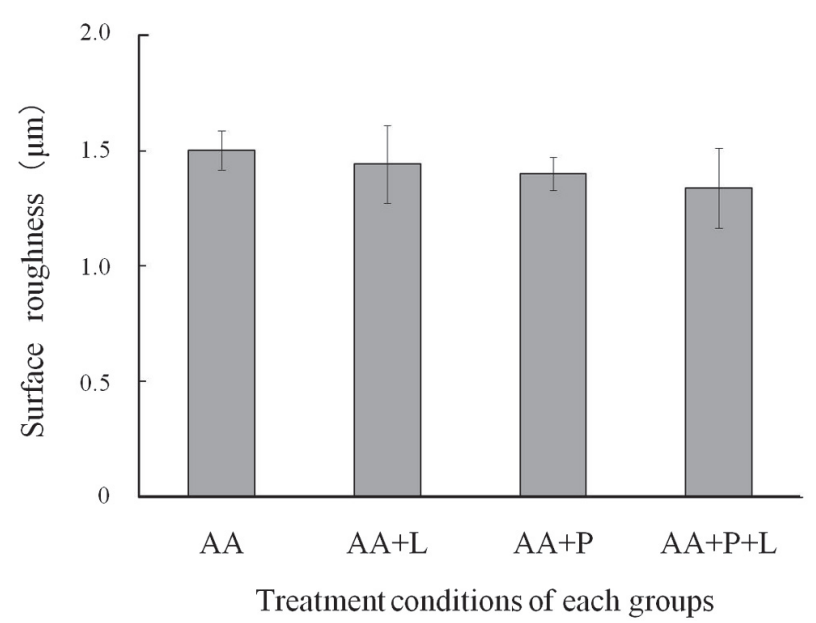

Fig. 5 Surface roughness $(\mathrm{Ra})$ values of all the test groups in this study.
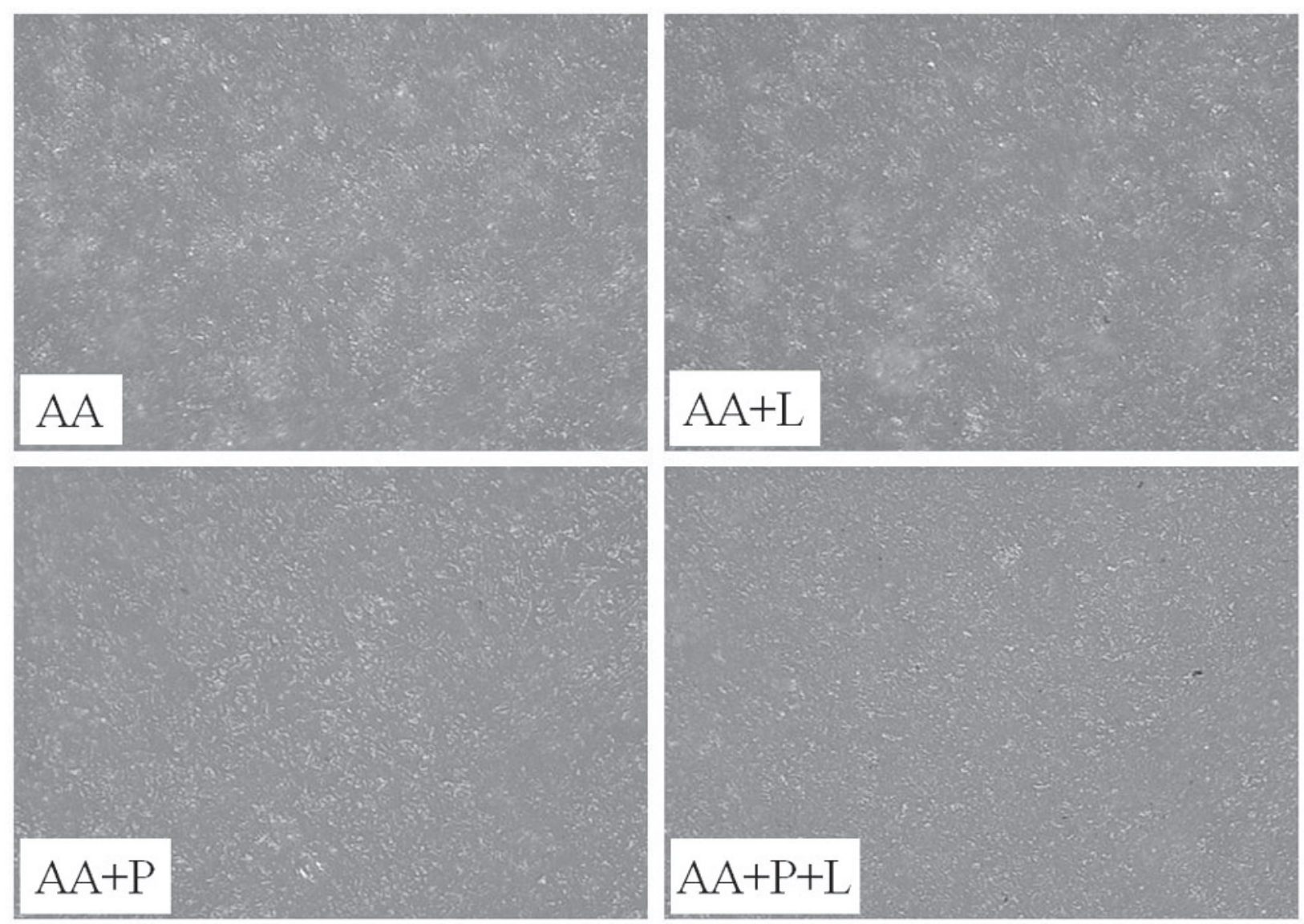

$1 \mu \mathrm{m}$

Fig. 6 Magnified images of the porcelain surface after each treatment (magnification $\times 1,000$ ). 


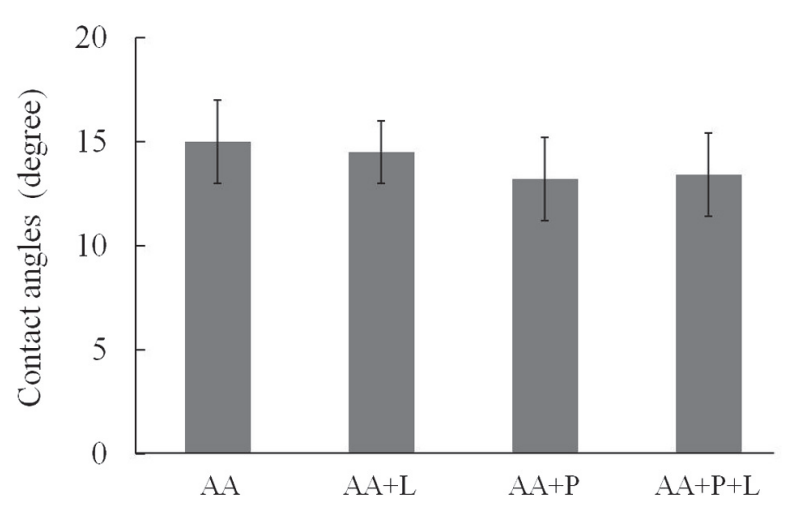

Treatment conditions of each groups

Fig. 7 Contact angles of all the test groups in this study.

subtle differences were detected based on the magnified images (Fig. 6). Increasing smooth surface morphology was observed in the following order: $\mathrm{AA}, \mathrm{AA}+\mathrm{L}, \mathrm{AA}+\mathrm{P}$, $\mathrm{AA}+\mathrm{P}+\mathrm{L}$.

3. Contact angle

Figure 7 shows the contact angle obtained for each surface treatment. The contact angles ranged between 13 and 15 degrees, and no significant differences were found among the four test groups.

4. Raman spectroscopy

Figure 8 shows the Raman spectra obtained for all the surface treatments in this study. Numerous peaks associated with the organic and inorganic components of the porcelain surface were detected. Notably, the peak at $3,750 \mathrm{~cm}^{-1}$, which is associated with isolated silanol (Si-OH), weakened in the following order: $\mathrm{AA}+\mathrm{L}$, $\mathrm{AA}, \mathrm{AA}+\mathrm{P}$, and $\mathrm{AA}+\mathrm{P}+\mathrm{L}$.

\section{DISCUSSION}

In the present study, carbon dioxide laser irradiation was applied to reinforce the adhesion between a porcelain substrate and composite resin for chairside porcelain repair. Carbon dioxide laser is one of the most popular and useful sources of coherent electromagnetic waves in the infrared spectrum. Carbon dioxide laser energy weakens rapidly in most biological tissues - regardless of tissue color- because it is readily absorbed by water ${ }^{16,17)}$. Therefore in wet tissues like the oral mucosa, a high percentage of carbon dioxide laser energy would be readily absorbed, which means that it augurs well as a safe and useful dental treatment.

To increase the bond strength between composite resins and silane-treated porcelain, it has been reported that heat treatment at $100^{\circ} \mathrm{C}$ effectively achieved this goal because it was able to consolidate three layers of silane into a monolayer without any interphase layer ${ }^{12)}$. However, in clinical settings, it is near impossible to limit the heating effect to a particular area without any

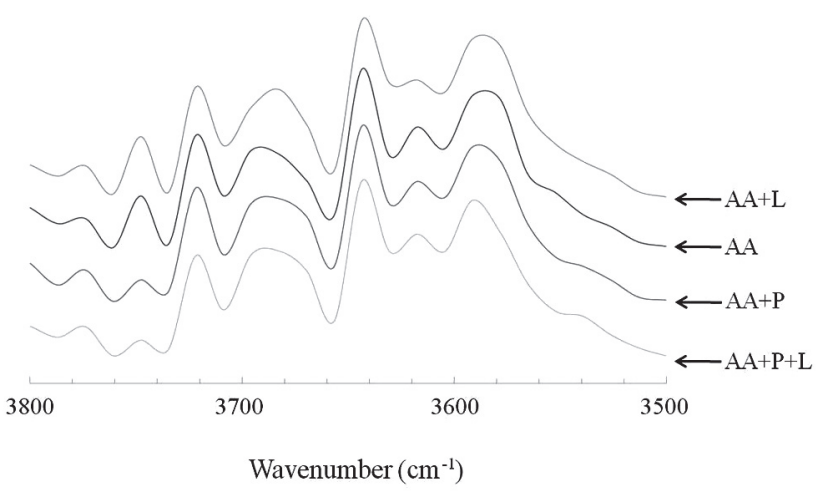

Fig. 8 Raman spectroscopic profiles of all the test groups in this study.

side effects to proximal tissue in the oral cavity. It has been widely reported that thermal side effects in dentin and/or enamel are often damaging and irreversible, including iatrogenic damage of the pulpal tissue ${ }^{18)}$.

On heat generated due to laser irradiation, carbon dioxide laser applied on the silane coupling layer on a porcelain surface purportedly did not cause any damage to the underlying or surrounding tissues. However, at higher doses, thermal effects from laser irradiation may lead to microcavities and/or cracks in hard dental tissue. In the present study, cracks and carbonization were observed on irradiated porcelain surfaces at output strength ranging between 1.2 and $1.5 \mathrm{~W}$. Based on the results obtained in this study, the optimal irradiation conditions for carbon dioxide laser were determined to be thus: output strength at $1.0 \mathrm{~W}$, irradiation time of 20 seconds, and irradiation distance at $30 \mathrm{~mm}$. These laser operating conditions would ensure that a clinically appropriate heat treatment is performed without causing any iatrogenic damage to enamel or the vulnerable dental pulp.

In the present study, the mechanism of adhesion enhancement between a porcelain substrate and a composite resin was investigated using both chemical and mechanical processes. Silane treatment was the chemical process, while air abrasion using alumina particles was the mechanical process. With air abrasion alone (AA group) and air abrasion followed by carbon dioxide laser irradiation (AA+L group), no adhesion enhancement was found. When carbon dioxide laser irradiation was coupled with silane treatment $(\mathrm{AA}+\mathrm{P}+\mathrm{L}$ group), adhesion enhancement was found. This was probably because of a catalyzing effect which followed the heat treatment using carbon dioxide laser irradiation. When bonding durability was assessed by thermal cycling, the shear bond strength of $\mathrm{AA}+\mathrm{P}+\mathrm{L}$ group before thermal cycling was found to be $15 \%$ higher than that of silane treatment only (AA+P group). After 2,000 thermal cycles, the shear bond strength of $\mathrm{AA}+\mathrm{P}+\mathrm{L}$ group was higher than the other 
test groups by more than 100\%.

The use of silane coupling agents is highly recommended in dental literature as a means to improve bonding between composite resins and porcelain ${ }^{19,20)}$. When a silane-treated porcelain surface was further coupled with an elevated temperature, the shear bond strength of composite resin to porcelain became markedly increased because of increase in crosslinked structure caused by the alignment of silane groups $^{21)}$. In the present study, carbon dioxide laser irradiation elevated the temperature of the porcelain surface and the shear bond strengths of $\mathrm{AA}+\mathrm{P}$ and $\mathrm{AA}+\mathrm{P}+\mathrm{L}$ groups were indeed significantly improved. This result indicated that carbon dioxide laser was capable of forming strong chemical bonds required for chairside porcelain repair.

Surface properties that would affect bond strength include surface roughness and the contact angle. In the present study, no significant differences $(p>0.05)$ in mean surface roughness were found among all the surface treatments. Similarly, no significant differences in mean contact angle were found among the four test groups. The contact angle is an indicator of the wettability of a surface, and it is used as an inverse measure of the bonding strength of various materials ${ }^{22,23)}$ : the lower the contact angle, the higher the bonding strength. Results of the present study thus showed that carbon dioxide laser irradiation had minimal impact on the contact angle of porcelain surfaces.

Raman spectroscopy is a useful, non-destructive technique which has been used to examine the compositional changes of porcelain surfaces ${ }^{24,25)}$. Since silane coupling agents improve the bonding of composite resins to porcelain, the characterization of silane coupling agent on the porcelain surface, particularly the bonding configuration of $\mathrm{Si}-\mathrm{OH}$ groups in Raman spectrum, would serve as a useful indicator of the bond strength between composite resin and porcelain ${ }^{26)}$. Si-OH bands can be located at several peaks, depending on their bonding configuration from the isolated to the hydrogen-bonded states. In the isolated state, whereby the isolated $\mathrm{Si}-\mathrm{OH}$ group is known as single silanol or free hydroxyl group, the peak is located at $3,750 \mathrm{~cm}^{-1}$. The isolated single silanol group shows high reactivity with silane coupling agents, such that the intensity of the Raman peak of isolated $\mathrm{Si}-\mathrm{OH}$ group decreases with increasing bond strength between the composite resin and porcelain ${ }^{27,28)}$. In the present study, the peak at $3,750 \mathrm{~cm}^{-1}$, which is associated with free isolated silanol ( $\mathrm{Si}-\mathrm{OH}$ ) groups, weakened in the following order: $\mathrm{AA}+\mathrm{L}, \mathrm{AA}, \mathrm{AA}+\mathrm{P}$, and $\mathrm{AA}+\mathrm{P}+\mathrm{L}$. This Raman spectroscopy result agreed seamlessly with the shear bond strength results shown in Fig. 3. In other words, carbon dioxide laser irradiation - which rendered heat treatment to the silane coupling agent layer on the porcelain substrateeffectively enhanced the bonding between composite resin and porcelain, thereby resulting in decreased isolated $\mathrm{Si}-\mathrm{OH}$ groups on the porcelain surface.

\section{CONCLUSION}

To the end of seeking an alternative, clinically acceptable mode of heating silane coupling agent layers, this study was limited to investigating the effect of carbon dioxide laser application as a post-silanization procedure. When silane-treated porcelain was irradiated with carbon dioxide laser, the shear bond strength between composite resin and porcelain was significantly increased, and that its shear bond strength was pronouncedly higher than other surface treatments after thermal cycling. Results showed that a combined treatment of silane application followed by laser irradiation augured well as an effective chairside porcelain repair procedure with a short working time and no side effects.

\section{ACKNOWLEDGMENTS}

The authors wish to express sincere thanks and gratitude to Professor Fumiaki Kawano, Tokushima University, for his very kind and generous assistance with the laser Raman measurement.

\section{REFERENCES}

1) Peumans M, Van Meerbeek B, Lambrechts P, Vanharle G. Porcelain veneers: a review of the literature. J Dent 2000; 28: 163-177.

2) Ulusoy M, Toksavul S. Fracture resistance of five different metal framework designs for metal-ceramic restorations. Int J Prosthodont 2002; 15: 571-574.

3) Kang MS, Ercoli C, Galindo DF, Graser GN, Moss ME, Tallents RH. Comparison of the load at failure of soldered and nonsoldered porcelain-fused-to-metal crowns. J Prosthet Dent 2003; 90: 235-240.

4) Michalakis KX, Stratos A, Hirayama H, Kang K, Touloumi F, Oishi Y. Fracture resistance of metal ceramic restorations with two different margin designs after exposure to masticatory simulation. J Prosthet Dent 2009; 102: 172-178.

5) Appeldoom RE, Wilwerding TM, Barkmeier WW. Bond strength of composite resin to porcelain with newer generation porcelain repair systems. J Prosthet Dent 1993; 70: 6-11.

6) Demirel F, Muhtaroğullari M, Yüksel G, Cekiç C. Microleakage study of 3 porcelain repair materials by autoradiography. Quintessence Int 2007; 38: 285-290.

7) Chung KH, Hwang YC. Bonding strengths of porcelain repair systems with various surface treatments. J Prosthet Dent 1997; 78: 267-274.

8) Suliman AH, Swift EJ Jr, Perdigao J. Effects of surface treatment and bonding agents on bond strength of composite resin to porcelain. J Prosthet Dent 1993; 70: 118-120.

9) Diaz-Arnold AM, Schneider RL, Aquilino SA. Bond strengths of intraoral porcelain repair materials. J Prosthet Dent 1989; 61: 305-309.

10) Roulet JF, Soderholm KJ, Longmate J. Effects of treatment and storage conditions on ceramic/composite bond strength. J Dent Res 1995; 74: 381-387.

11) Blatz MB, Sadan A, Blatz U. The effect of silica coating on the resin bond to the intaglio surface of Procera AllCeram restorations. Quintessence Int 2003; 34: 542-547.

12) Barghi N, Berry T, Chung K. Effects of timing and heat treatment of silanated porcelain on the bond strength. J 
Oral Rehabil 2000; 27: 407-412.

13) Goldman L, Hornby P, Meyer R, Goldman B. Impact of the laser on dental caries. Nature 1964; 203: 417.

14) Benedetto $\mathrm{MD}$, Antonson $\mathrm{DE}$. Use of $\mathrm{CO}_{2}$ laser for visible detection of enamel fissure caries. Quintessence Int 1988; 19: $187-190$

15) Witteman WJ. The $\mathrm{CO}_{2}$ laser. In: Shimoda $\mathrm{K}$, editor. Springer series in optical sciences. Vol 53. Berlin: Springer; 1987. p. 1-309.

16) Kutch VK. Lasers in dentistry: comparing wavelengths. J Am Dent Assoc 1993; 124: 49-54.

17) Pick RM. Using laser in clinical dental practice. J Am Dent Assoc 1993; 124: 34-47.

18) Jeffrey IWM, Lawrenson B, Saunders EM, Longbottom C. Dentinal temperature transients caused by exposure to $\mathrm{CO}_{2}$ laser irradiation and possible pulpal damage. J Dent 1990; 18: 31-36.

19) Hayakawa $T$, Horie $K$, Aida M, Kanaya H, Kobayashi T, Murata Y. The influence of surface conditions and silane agents on the bond of resin to dental porcelain. Dent Mater 1992; 8: 238-240.

20) Kupiec KA, Wuertz KM, Barkmeier WW, Wilwerding TM. Evaluation of porcelain surface treatments and agents for composite-to-porcelain repair. J Prosthet Dent 1996; 76: 119-124.

21) Hooshmand T, van Noort R, Keshvad A. Bond durability of the resin-bonded and silane treated ceramic surface. Dent Mater 2002; 18: 179-188.

22) Nurhaerani, Arita K, Shinonaga Y, Nishino M. Plasmabased fluorine ion implantation into dental materials for inhibition of bacterial adhesion. Dent Mater J 2006; 25: 684-692.

23) Sipahi C, Anil N, Bayramli E. The effect of acquired salivary pellicle on the surface free energy and wettability of different denture base materials. J Dent 2001; 29: 197204.

24) Kawano F, Hanawa T, Kon M, Oka K, Tomotake Y, Asaoka K, Ichikawa T, Matsumoto N. Estimation of residual stress in dental porcelain by laser-Raman spectroscopy. Dent Mater J 1998; 17: 41-50.

25) Anedda A, Carbonaro CM, Clemente F, Corda L, Corpino R, Ricci PC. Surface hydroxyls in porous silica: a Raman spectroscopy study. Mater Sci Eng 2003; 23: 1069-1072.

26) Shih PTK, Koenig JL. Raman studies of the hydrolysis of silane coupling agents. Mater Sci Eng 1975; 20: 137-143.

27) Brinker CJ, Scherer GW. Sol-gel science: The physics and chemistry of sol-gel processing. 1st ed. London: Academic Press; 1990. p. 108-202.

28) Aguiar H, Serra J, Gonzalez P, Leon B. Structural study of sol-gel silicate glasses by IR and Raman spectroscopies. J Non-Crys Sol 2009; 355: 475-480. 